\title{
KONTRUKSI MAKNA PEGIAT PERPUSTAKAAN JALANAN (STUDI FENOMENOLOGI TENTANG KONTRUKSI MAKNA PEGIAT PERPUSTAKAAN JALANAN DI KOTA BANDUNG)
}

\author{
Nugraha Dwi Saputra*, Ninis Agustini Damayani*, Asep Saeful Rahman*
}

Pengutipan: Saputra, N. D., Damayani, N. A., \& Rahman, A. S. (2017). Kontruksi Makna Pegiat Perpustakaan Jalanan (Studi Fenomenologi tentang Kontruksi Makna Pegiat Perpustakaan Jalanan di Kota Bandung). Khizanah Al-Hikmah : Jurnal Ilmu Perpustakaan, Informasi, dan Kearsipan. 5(2), 152-159.

DOI: http://doi.org/10.24252/kah.v5i2a2

*Program Studi Ilmu Perpustakaan Fakultas Ilmu Komunikasi Universitas Padjajaran agadwi22@gmail.com, ninis_agustini@yahoo.com,asep.saefulr@gmail.com

\section{ABSTRAK}

Penelitian ini tentang kontruksi makna para pegiat perpustakaan jalanan dilakukan di Perpustakaan Jalanan yang ada di Kota Bandung. Tujuan dari penelitian ini untuk mengetahui makna diri pegiat perpustakaan jalanan, motif pendirian Perpustakaan Jalanan Bandung, dan pengalaman mengelola Perpustakaan Jalanan Bandung. Metode penelitian yang digunakan ialah kualitatif dengan pendekatan fenomenologi. Hasil Penelitian ini menemukan adanya tiga makna pegiat perpustakaan jalanan yaitu penyedia ruang alternatif, penyegar pikiran dan menjadi seorang manusia baru. Motif tujuan didirikannya Perpustakaan Jalanan Bandung ialah mempermudah akses informasi bagi semua orang dan membuat tempat baca alternatif. Kendala dalam mengelola Perpustakaan Jalanan Bandung ialah pemukulan oleh tentara, persepsi negatif tentang perpustakaan jalanan, kredibilitas buku masih dipertanyakan dan buku-buku sering hilang.

Kata kunci: Pegiat Literasi, Perpustakaan Jalanan, Taman Bacaan Masyarakat, Kontruksi Makna

\section{ABSTRACT}

The research on the construction of meaning of street library activists conducted in the Library Street in Bandung. The purpose of this study is to find out the meaning of self-campaigning street librarian, the motive of Bandung Street Library establishment, and experience of managing the Bandung Street Library. The research method used is qualitative with phenomenology approach. The results of this study found the three meanings of street library activists are alternative space providers, refreshment of mind and become a new human being. The motive for the purpose of the establishment of Bandung Street Library is to make it easier to access information for everyone and make alternative reading places. Constraints in managing the Bandung Street Library is beating by soldiers, negative perceptions about street libraries, the credibility of books is still questionable and books are often lost.

Keywords: Literacy Activist, Street Library, Urban Library, Meaning Contruction

\section{LATAR BELAKANG}

Perpustakaan Jalanan di Kota Bandung berada di seputaran Kota Bandung, Jawa Barat. Lokasi dari perpustakaan jalanan di Kota Bandung salah satunya berada di taman cikapayang di bawah fly over Surapati, dekat dengan tulisan taman DAGO. Perpustakaan
Jalanan Bandung buka setiap malam Minggu pukul 16.00 sampai 23.00. Keunikan dari Perpustakaan Jalanan Bandung ialah karena didirikan sejak tahun 2010. Hal tersebut menjadikan Perpustakaan Jalanan Bandung sebagai perpustakaan jalanan tertua di Indonesia. Perpustakaan Jalanan Bandung menyediakan berbagai jenis buku bacaan 
dengan hampir semua genre mulai dari novel, politik, keagamaan, pendidikan hingga bukubuku kiri yang jarang ditemui di toko buku. Sekitar 400 eksemplar buku disediakan pada pengunjungnya ketika malam Minggu tiba. Kegiatan utama dari Perpustakaan Jalanan Bandung ialah menyediakan bahan bacaan untuk masyarakat yang ingin membaca dan meminjam buku dengan tanpa menggunakan sistem keanggotaan. Selain kegiatan utama berupa lapak buku gratis, Perpustakaan Jalanan Bandung juga melakukan berbagai kegiatan lain seperti berbagi buku bacaan, kegiatan kemanusiaan, acara seni dan diskusi.

Pendirian Perpustakaan Jalanan Bandung muncul dari tiga orang pendirinya. Ketiganya merupakan mahasiswa dari Universitas Pendidikan Indonesia (UPI). Berawal dari tiga orang mahasiwa ini kemudian banyak orang yang tertarik bergabung, termasuk empat orang pengurus Perpustakaan Jalanan Bandung saat ini. Dalam perjalanan tujuh tahun mengelola Perpustakaān Jalanan Bandung, berbagai stigma negatif tentang adanya Perpustakaan Jalanan Bandung menjadi cerita lain dalam pengelolaan Perpustakaan Jalanan Bandung.

Perpustakaan jalanan menjadi perbincangan yang ramai hampir diseluruh Indonesia karena adanya insiden dengan aparat TNI. Hingga pada akhir tahun 2016 perpustakaan jalanan menjadi fenomena tersendiri bagi dunia literasi Indonesia. Dengan konsep membawa perpustakaan dekat dengan masyarakat, perpustakaan jalanan muncul dibanyak wilayah tanah air. Banyak perpustakaan jalananan baru muncul pada akhir 2016 di berbagai wilayah Indonesia seperti Aceh, Makasar, Jakarta, Bandung, Yogyakarta, Malang, Cirebon, Kediri serta daerah lainnya.

Perpustakaan jalanan muncul sebagai istilah tempat yang menyediakan buku-buku bacaan yang berlokasi di pinggir jalan. Perpustakaan jalanan melakukan kegiatannya dengan menggelar lapak di pinggir jalan dengan alas terpal dan menjajakan buku yang dimilikinya.
Perpustakaan jalanan ini biasanya dididirikan oleh sekelompok orang atau komunitas yang peduli akan minat baca masyarakat tanpa adanya niat untuk memperoleh keuntungan.

Perpustakaan jalanan pada dasarnya memiliki tujuan yang sama dengan TBM ataupun perpustakaan umum yaitu untuk meningkatkan minat baca masyarakat. Adanya perpustakaan jalanan sedikit banyak bisa mengatasi permasalahan rendahnya minat baca masyarakat di Indonesia. Dimana diketahui bahwa angka minat baca masyarakat Indonesia dapat dibilang cukup rendah.

Menurut survey yang dilakukan Central Connecticut State University di New Britain yang dimuat dalam berita Media Indonesia tanggal 30/08/2016 menempatkan Indonesia di peringkat 60 dari 61 negara terkait minat baca. Data tersebut didukung pula oleh data UNESCO yāng dimuat dalam berita Sragen Pos 07/09/2015, dimana disebutkan bahwa indeks membaca orang Indonesia hanya 0,001 yang berarti dari 1.000 orang yang ada di Indonesia hanya ada satu orang yang memiliki minat membaca buku.

Permasalahan minat baca yang rendah di Indonesia terjadi karena dua sebab utama yaitu personal dan institusional. Sebab personal berasal dari dalam diri manusia dan sebab institusional disebabkan oleh tidak adanya fasilitas membaca. Dari sebab institusional itulah kemudian muncul perpustakaan jalanan yang mengakomodasi keinginan masyarakat untuk membaca dengan menyediakan bahan bacaan dekat dengan masyarakat, seperti di taman kota ataupun alun-alun. Dari pemaparan tersebut diketahui bahwa perpustakaan jalanan telah menjadi fenomena tersendiri bagi dunia literasi Indonesia.

Perpustakaan jalanan menjadi salah satu solusi dari sulitnya masyarakat umum dalam mendapatkan bahan bacaan. Perpustakaan jalanan menyediakan bahan bacaan di tengah keramaian masyarakat dan dikelola secara sukarela oleh sekelompok orang atau 
komunitas tanpa adanya niat untuk mencari keuntungan material.

Saat ini banyak orang yang kurang mempedulikan tentang pentingnya membaca akan tetapi para pegiat perpustakaan jalanan muncul dengan menyediakan berbagai bahan bacaan sebagai salah satu solusi mengatasi minat baca masyarakat yang rendah. Hal itu menjadikannya topik yang menarik untuk diangkat kedalam penelitian, terlebih lagi saat ini penelitian dengan topik perpustakaan jalanan belum banyak dilakukan. Maka dari itu peneliti tertarik untuk meneliti kontruksi makna pegiat perpustakaan jalanan dengan studi fenomenologi tentang kontruksi makna pegiat Perpustakaan Jalanan di Kota Bandung.

Adapun tujuan yang hendak dicapai ialah untuk mengetahui makna pegiat perpustakaan jalanan bagi dirinya, untuk mengetahui motif yang mendasari pendirian Perpustakaan Jalanan Bandung dan untuk mengetahui pengalaman mengelola Perpustakaan Jalanan Bandung.

\section{METODE PENELITIAN}

Penelitian ini dilakukan dengan menggunakan metode kualitatif dengan pendekatan fenomenologi. Pendekatan fenomenologi dipilih karena peneliti ingin mengetahui makna, motif dan pengalaman dari individu yang menjadi pegiat Perpustakaan Jalanan Bandung.

Subjek penelitian ini ialah empat pengurus Perpustakaan Jalanan Bandung yang telah memiliki pengalaman minimal tiga tahun dalam mengelola Perpustakaan Jalanan Bandung. Penentuan subjek pada penelitian ini dilakukan dengan cara pursposive sampling atau sampel bertujuan. Dengan menggunakan sampel bertujuan maka akan bisa didapatkan subjek penelitian yang sesuai dengan kebutuhan.

Prosedur pengumpulan data pada penelitian ini menggunakan tiga teknik yaitu wawancara, observasi dan dokumentasi.
Wawancara dilakukan secara langsung melalui tatap muka dengan para key informan dengan panduan wawancara semi terstruktur. Sedangkan Jenis observasi yang digunakan pada penilitian ini ialah observasi partisipan. Prosedur pengumpulan data yang terakhir ialah studi dokumentasi yang didapatkan dari foto kegiatan penelitian, informasi dari media sosial dan web Perpustakaan Jalanan Bandung serta sumber informasi lain yang mendukung penelitian ini.

Teknik keabsahan data pada penelitian ini mengikuti prosedur yang digariskan oleh polkinghorn yaitu, bahwa kriteria utama untuk menguji keabsahan data adalah dengan memastikan bahwa data-data yang ada tersebut sungguh-sungguh berdasar dan didukung fakta (Polkinghorn dalam Kuswarno 2009 : 75).

Selain itu pemeriksaan keabsahan data juga dilakukan dengan teknik trianggulasi sumber dengan narasumber Ibu Neti Supriyati yang berasal dari Dinas Perpustakaan dan Kearsipan Kota Bandung (DISPUSIP BDG) dan Bapak Adri Yanto yang merupakan ahli dari keilmuan perpustakaan yang berasal dari Program Studi Ilmu Perpüstakaan Universitas Padjajaran.

Dalam menganalisis data hasil wawancara, peneliti berpedoman pada tahapan-tahapan yang disarikan oleh Creswell (dalam Kuswarno 2009 : 72) untuk teknik analisis data fenomenologi yang dimulai dari membuat deskripsi lengkap atas pengalaman key informan, mengidentifikasi pernyataan yang muncul dan membuat daftar pernyataan penting, mengelompokan pernyataan menjadi kesatuan makna (meaning unit) dan membuat deskripsi dalam pengalaman tersebut (textural description), melakukan refleksi atas deskripsi yang telah dibuat dan mengkontruksi bagaimana fenomena tersebut dialami serta yang terakhir ialah mengkonstruksikan makna dari pengalaman tersebut.

Penelitian ini sendiri dilakukan di Perpustakaan Jalanan Bandung yang biasa 
menggelar lapak bukunya setiap malam Minggu di taman cikapayang, dibawah flyover Surapati, Kota Bandung, Jawa Barat. Penelitian dilakukan dari bulan Desember 2016 hingga Juni 2017.

\section{HASIL PENELITIAN DAN PEMBAHASAN}

\section{a. Makna Pegiat Perpustakaan Jalanan}

Berdasarkan penelitian yang telah dilakukan diketahui bahwa terdapat berbagai pendapat dari para pegiat Perpustakaan Jalanan Bandung tentang cara mereka memaknai aktivitasnya sebagai pegiat perpustakaan jalanan. Dari pendapat yang diungkapkan oleh empat pegiat Perpustakaan Jalanan Bandung dapat dikelompokan menjadi tiga makna pegiat perpustakaan jalanan yaitu penyedia ruang alternatif, penyegar pikiran, dan manusia baru.

Sebagai penyedia ruang alternatif pegiat perpustakaan jalanan menyediakan ruang alternatif bagi masyarakat untuk melakukan berbagai hal mulai hanya tempat kumpul, berbagi informasi dengan orang lain hingga melakukan pelatihan atau workshop bagi teman-teman perpustakaan jalanan dan masyarakat umum.

Kemudian sebagai penyegar pikiran memiliki arti bahwa dengan menjadi pegiat perpustakaan jalanan menurut mereka merupakan sesuatu yang dapat menyegarkan pikiran dari rutinitas yang ada melalui kegiatan lapak, bertemu orang dan mengobrol bersama teman. Pemaknaan terakhir ialah sebagai manusia baru yang berarti dengan menjadi pegiat perpustakaan jalanan maka bisa mendapatkan hal seperti informasi, pengalaman, hingga mudahnya mendapatkan teman dan membuat jejaring yang sulit dilakukan apabila tidak menjadi seorang pegiat perpustakaan jalanan.

Sebagaimana yang diungkapkan oleh Atwar Badjari (Bajari 2010 : 85) bahwa pembentukan makna sendiri merupakan proses produksi dimana individu berusaha memahami sesuatu dan menyampaikannya kepada orang lain sebagai bagian dari proses sosial sehari-hari. Maka dari itu berbagai pengalaman pada saat mereka menjadi pegiat perpustakaan jalanan akan menjadi makna diri bagi masing-masing individu apabila para pegiat perpustakaan jalanan berusaha memahami pengalaman yang dialaminya tersebut.

Makna diri bukan terletak pada tindakan yang pernah mereka lakukan akan tetapi makna diri pegiat perpustakaan jalanan tersebut muncul dari hasil konstruksi makna dalam diri manusia itu sendiri dalam hal ini ialah individu Pegiat Perpustakaan Jalanan Bandung. Hal itu sesuai dengan Model proses makna yang pertama menurut Wendell Johnson yang dikutip oleh sobur bahwa Makna ada dalam diri manusia. Makna tidak terletak pada kata-kata melainkan pada manusia (Sobur 2003 : 258).

Selain itu Pembentukan makna pada setiap individu dipengaruhi oleh faktor yang berbeda-beda dan hal tersebutlah yang membuat pemaknaan diri pegiat perpustakaan jalanan oleh setiap individu di Perpustakaan Jalanan Bandung menjadi beragam dan bisa berbeda meskipun yang dimaknainya sama.

Hal tersebut sesuai dengan pendapat Sutarno AW (2010 : 136) yang mengatakan bahwa makna pesan komunikasi verbal tergantung pada lingkungan psikologis, fisik, sosiologis, budaya dan antropologis yang dimiliki oleh manusia. Dan pendapat lain yang mendukung pernyaataan tersebut ialah pendapat menurut Atwar Bajari (Bajari 2010 : 85) yang mengatakan bahwa pembentukan makna oleh individu melibatkan berbagai faktor seperti lingkungan, sistem yang berkembang, dan kapasitas dari individu seperti faktor personal individu.

Berdasarkan pembahasan diatas diketahui bahwa terdapat tiga makna pegiat perpustakaan jalanan yaitu penyedia ruang alternatif, penyegar pikiran dan manusia baru. Ketiga makna tersebut apabila ditampilkan dalam bentuk gambar, maka 
makna pegiat Perpustakaan Jalanan Bandung bagi diri mereka nampak sebagai berikut:

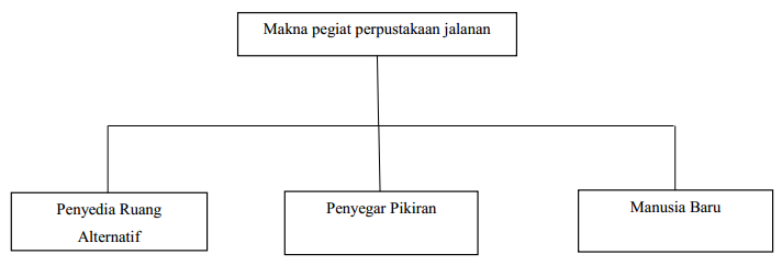

Gambar 1. Makna Pegiat Perpustakaan

Jalanan

\section{b. Motif Pendirian Perpustakaan Jalanan Bandung}

Berdasarkan penelitian yang telah dilakukan terdapat berbagai pendapat mengenai motif didirikannya Perpustakaan Jalanan Bandung. Temuan motif tersebut bisa dikelompokan menjadi alasan dan tujuan didirikannya Perpustakaan Jalanan Bandung.

Untuk alasan dari didirikannya Perpustakaan Jalanan Bandung ditemukan adanya tiga alasan yaitu masyarakat sulit mengakses informasi, banyak buku pribadi tidak terpakai dan kritik terhadap ruang publik. Sedangkan untuk tujuan didirikannya Perpustakaan Jalanan Bandung ditemukan adanya dua tujuan utama yaitu mempermudah akses informasi bagi semua orang dan membuat tempat baca alternatif.

Menurut Uno B Hamzah motif digolongkan menjadi dua macam, yaitu motif intrinsik dan motif ekstrinsik. Motif intrinsik, timbulnya tidak memerlukan rangsangan dari luar karena memang telah ada dalam diri individu sendiri, yaitu sesuai atau sejalan dengan kebutuhannya. Sedangkan motif ekstrinsik timbul karena adanya rangsangan dari luar individu.(Uno 2013 : 4)

Dengan demikian bila dikaitkan dengan hasil penelitian bahwa secara umum kebutuhan manusia bermacam-macam, namun kebutuhan yang mendorong para pendiri Perpustakaan Jalanan Bandung untuk membuat perpustakaan jalanan dikarenakan adanya dua motif yaitu motif alasan yang timbul dalam diri manusia dan motif tujuan yang berasal dari luar.

Sedangkan menurut fenomenologi Schutz disebut dengan in order to motive dan because motive. Because motive sendiri merupakan motif alasan dimana seorang individu melakukan suatu tindakan karena adanya dorongan masa lalu yang membuatnya melakukan tindakan tersebut atau dengan kata lain because motive menyebabkan seseorang melakukan tindakan tertentu. Dalam konteks penelitian ini maka because motive atau motif intrinsik ini berkaitan dengan alasan para pendiri Perpustakaan Jalanan Bandung membuat tempat bernama Perpustakaan Jalanan Bandung. Sedangkan in order to motive merupakan motif yang menarik seseorang untuk melakukan suatu tindakan. In order motive sendiri mengacu pada hal yang ingin dicapai seseorang di masa depan dengan melakukan suatu tindakan.

Dengan kata lain in order to motive ini berkaitan dengan maksud, rencana, harapan, dan minat seseorang. Dalam konteks penelitian ini maka in order motive ialah tujuan dan harapan yang ingin dicapai oleh para pendiri Perpustakaan Jalanan Bandung dengan membuat perpustakaan jalanan.

Berdasarkan penjelasan tersebut di atas maka temuan motif yang termasuk kedalam jenis because motive atau motif alasan ialah masyarakat sulit mengakses informasi, banyak buku pribadi tidak terpakai dan kritik terhadap ruang publik. Sedangkan yang termasuk kedalam jenis in order to motive atau motif tujuan ialah mempermudah akses informasi bagi semua orang dan membuat tempat baca alternatif. Dan apabila ditampilkan dalam bentuk gambar, maka motif pendian Perpustakaan Jalanan Bandung Nampak seperti bagan berikut ini: 


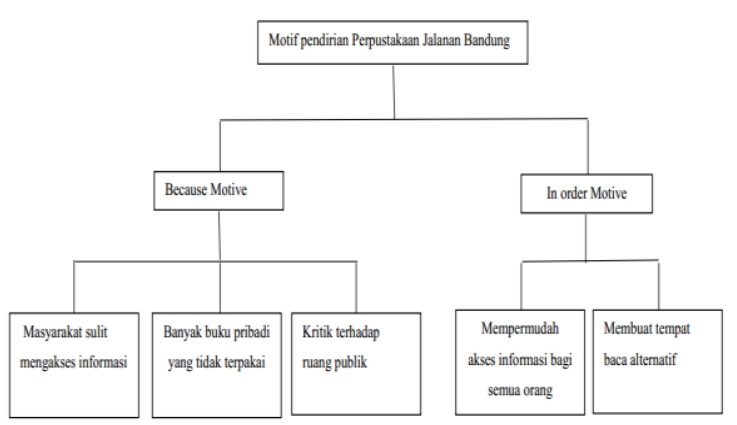

Gambar 2. Motif Pendirian Perpustakaan Jalanan Bandung

\section{c. Pengalaman Mengelola Perpustakaan Jalanan Bandung}

Perpustakaan Jalanan Bandung telah berjalan selama tujuh tahun sejak pertama kali didirikan pada tahun 2010. Dalam tujuh tahun penyelenggaraan Perpustakaan Jalanan Bandung tentu banyak peristiwa dan kejadian yang dialami oleh para pegiat Perpustakaan Jalanan Bandung itu sendiri. Peristiwa yang terjadi selama mereka mengelola Perpustakaan Jalanan Bandung menjadi pengalaman dalam setiap individu pegiat Perpustakaan Jalanan Bandung.

Menurut schutz: behavior is an experience of consciousness that bestows meaning through spontaneous activity, yang berarti perilaku adalah pengalaman dari kesadaran yang memberikan makna melalui aktivitas yang bersifat spontan (Schutz 1972 : 6).

Dengan demikian, dapat dikatakan pengalaman menjadi pondasi bagi individu dalam melakukan suatu tindakan. Setiap peristiwa yang dialami akan menjadi sebuah pengalaman bagi individu. Pengalaman yang diperoleh mengandung suatu informasi atau pesan tertentu. Informasi ini akan diolah menjadi pengetahuan.

Oleh karena itu berbagai peristiwa yang dialami dapat menambah pengetahuan individu. Maka setiap kejadian yang terjadi pada saat mengelola Perpustakaan Jalanan Bandung menjadi pengalaman bagi pegiat Perpustakaan Jalanan Bandung.

Dari pengalaman mengelola Perpustakaan Jalanan Bandung tersebut mengandung informasi yang menjadi pengetahuan bagi setiap individu pegiat Perpustakaan Jalanan Bandung. Banyaknya peristiwa yang terjadi saat mengelola Perpustakaan Jalanan Bandung akan menambah banyaknya pengetahuan bagi pegiat Perpustakaan Jalanan Bandung baik itu pengetahuan dari berbagai kegiatan yang pernah dilakukan dan kendala yang pernah dirasakan selama mengelola Perpustakaan Jalanan Bandung selama ini.

Dalam konteks penelitian ini peneliti membagi pengalaman Pegiat Perpustakaan Jalanan Bandung menjadi dua yaitu kegiatan yang pernah dilakukan oleh Perpustakaan Jalanan Bandung selama tujuh tahun berdiri dan kendala yang dihadapi selama mengelola Perpustakaan Jalanan Bandung. Dengan membagi kegiatan yang dilakukan oleh Perpustakaan Jalanan Bandung dan kendala yang dihadapi maka dapat mengetahui pengalaman mengelola Perpustakaan Jalanan Bandung secara menyeluruh.

Berdasarkan hasil penelitian, peneliti telah mengkategorisasikan kegiatan yang pernah dilakukan Perpustakaan Jalanan Bandung dalam pengelolaannya selama tujuh tahun, yaitu sebagai berikut. Kegiatan yang dilakukan Perpustakaan Jalanan Bandung ialah menggelar lapak buku gratis dimana masyarakat bisa membaca dan meminjam buku secara gratis tanpa adanya syarat keanggotaan, mengadakan acara diskusi dan sharing informasi dimana diskusi ini bisa dilakukan secara spontan ataupun direncanakan dan bisa diikuti oleh siapapun tanpa memandang latar belakangnya, membuat kegiatan pagelaran seni yang didalamnya terdapat kegiatan pameran karya, pertunjukan musik dan teatrikal, mengadakan acara berbagi dengan sesama berupa pembagian makanan gratis kepada masyarakat dan pembagian buku kepada perpustakaan jalanan dan TBM yang membutuhkan, serta mengadakan acara solidaritas seperti solidaritas HAM dan penggalangan bantuan untuk korban bencana. 
Sedangkan kendala yang dihadapi selama tujuh tahun mengelola perpustakaan jalanan bandung ialah pemukulan oleh tentara yang terjadi pada akhir tahun 2016 yang mengakibatkan turunnya jumlah pengunjung Perpustakaan Jalanan Bandung. Statement negatif tentang perpustakaan jalanan sepeti Perpustakaan Jalanan Bandung dianggap tidak memiliki manfaat bagi masyarakat, mengganggu pejalan kaki, dianggap menimbulkan kemacetan, serta Statement yang mengatakan Perpustakaan Jalanan Bandung menjadi kedok bagi geng motor.

Kredibilitas buku dipertanyakan dimana banyak pihak yang menganggap bahwa buku-buku di perpustakaan jalanan mengandung informasi yang dilarang disebarkan kepada masyarakat. Kendala yang terakhir ialah banyak buku yang hilang karena tidak dikembalikan oleh peminjam buku. Apabila kesemua kegiatan Perpustakaan Jalanan Bandung dan kendala dalam mengelola Perpustakaan Jalanan Bandung ditampilkan dalam bentuk gambar, maka hal tersebut akan nampak seperti bagan berikut ini.

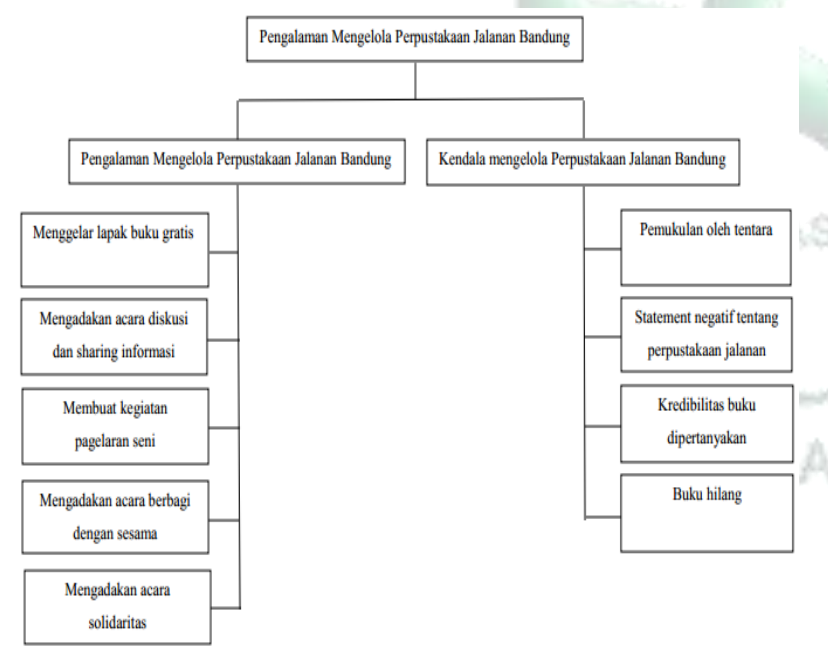

Gambar 3. Pengalaman Mengelola Perpustakaan Jalanan Bandung

\section{KESIMPULAN DAN SARAN}

Berdasarkan hasil penelitian dan pembahasan diatas dapat disimpulkan bahwa makna pegiat perpustakaan jalanan bagi dirinya adalah penyedia ruang alternatif, penyegar pikiran dan manusia baru.
Berkaitan dengan motif pendirian perpustakaan Jalanan Bandung sendiri, terdapat adanya dua motif utama yaitu motif alasan atau Because motive yang terdiri dari sulitnya masyarakat mengakses informasi, banyak buku pribadi yang tidak terpakai, dan kritik terhadap ruang publik.

Sedangkan motif tujuan atau in order to motive terdiri dari mempermudah akses informasi bagi semua orang dan membuat tempat baca alternatif. Selama tujuh tahun mengelola Perpustakaan Jalanan Bandung banyak kegiatan yang telah dilakukan dan berbagai kendala yang pernah dirasakan dalam mengelola Perpustakaan Jalanan Bandung.

Kegiatan yang dilakukan Perpustakaan Jalanan Bandung ialah menggelar lapak buku gratis, mengadakan acara diskusi dan sharing informasi, membuat kegiatan pagelaran seni, mengadakan acara berbagi dengan sesama, serta mengadakan acara solidaritas. Sedangkan kendala dalam mengelola Perpustakaan Jalanan Bandung ialah pemukulan oleh tentara, Statement negatif tentang perpustakaan jalanan, kredibilitas buku dipertanyakan dan buku hilang.

Berdasarkan berbagai temuan masalah dalam penelitian ini, peneliti menyarankan beberapa hal yaitu sebaiknya pegiat Perpustakaan Jalanan Bandung lebih memaknai aktivitasnya untuk melakukan gerakan literasi dan mengkampanyekan pentingnya membaca bagi masyarakat agar masyarakat semakin banyak yang datang dan membaca buku di Perpustakaan Jalanan Bandung.

Selain itu sebaiknya motif pendirian Perpustakaan Jalanan Bandung bisa ditambah yaitu berkaitan dengan gerakan literasi dan minat baca masyarakat agar Perpustakaan Jalanan Bandung bisa memiliki fokus kearah tersebut tidak hanya fokus pada kegiatan sosial. Terakhir sebaiknya Perpustakaan Jalanan Bandung mulai merapikan bukubuku agar peristiwa kehilangan buku di 
Perpustakaan Jalanan Bandung bisa diminimalisir dan sebaiknya Perpustakaan Jalanan Bandung menjalin komunikasi dengan pihak terkait misalnya Dinas Perpustakaan dan Arsip Kota Bandung untuk menemukan solusi dari masalah yang ada agar masyarakat tidak takut untuk datang ke Perpustakaan Jalanan Bandung.

\section{DAFTAR PUSTAKA}

Alex, S. (2003). Psikologi Umum. Bandung: Pustaka Setia.

Bajari, A. (2010). Komunikasi Kontekstual. Bandung: Rosda

Djauhar, A. (2017, 4 Maret). Bangsa Ini Dilarang Menjadi Cerdas. Diakses dari http://www.sragenpos.com/2015/kolo $\mathrm{m}$-bangsa-ini-dilarang-menjadi-cerdas640098.

Ferdiyanto, R. (2017, 4 Maret). Minat Baca Indonesia, Peringkat 60 dari 61 Negara. Diakses dari http://www.Mediaindonesia.com/new $\mathrm{s} / \mathrm{read} / \mathrm{minat}$-baca-indonesia-pengkat60-dari-61-negara/2016-08-30.

Kuswarno, E. (2009). Metodologi Penelitian Komunikasi Fenomenologi. Bandung: Widya Padjajaran.

Suranto, A. W. (2010). Komunikasi Sosial Budaya. Yogyakarta: Graha Ilmu.

Uno, H. B. (2013). Teori Motivasi dan Pengukurannya. Jakarta: Bumi Aksara. 